\title{
Article \\ Genetic Analysis of Hexaploid Wheat (Triticum aestivum L.) Using the Complete Sequencing of Chloroplast DNA and Haplotype Analysis of the Wknox1 Gene
}

\author{
Mari Gogniashvili ${ }^{1, *(\mathbb{D}}$, Yoshihiro Matsuoka ${ }^{2} \mathbb{D}$ and Tengiz Beridze ${ }^{1}(\mathbb{D}$ \\ 1 Institute of Molecular Genetics, Agricultural University of Georgia, \#240 D. Aghmashenebeli Av, \\ Tbilisi 0131, Georgia; t.beridze@agruni.edu.ge \\ 2 Graduate School of Agricultural Science, Kobe University, Rokko, Nada, Kobe 657-8501, Japan; \\ pinehill@port.kobe-u.ac.jp \\ * Correspondence: m.gogniashvili@agruni.edu.ge; Tel.: +995-599-234-855
}

check for updates

Citation: Gogniashvili, M.; Matsuoka, Y.; Beridze, T. Genetic Analysis of Hexaploid Wheat (Triticum aestivum L.) Using the Complete Sequencing of Chloroplast DNA and Haplotype Analysis of the Wknox1 Gene. Int. J. Mol. Sci. 2021, 22, 12723. https://doi.org/10.3390/ ijms222312723

Academic Editor: Sukhwinder Singh

Received: 30 September 2021

Accepted: 6 November 2021

Published: 24 November 2021

Publisher's Note: MDPI stays neutral with regard to jurisdictional claims in published maps and institutional affiliations.

Copyright: (c) 2021 by the authors Licensee MDPI, Basel, Switzerland. This article is an open access article distributed under the terms and conditions of the Creative Commons Attribution (CC BY) license (https:// creativecommons.org/licenses/by/ $4.0 /)$

\begin{abstract}
The aim of the presented study is a genetic characterization of the hexaploid wheat Triticum aestivum $\mathrm{L}$. Two approaches were used for the genealogical study of hexaploid wheats-the complete sequencing of chloroplast DNA and PCR-based haplotype analysis of the fourth intron of Wknox $1 d$ and of the fifth-to-sixth-exon region of Wknox $1 b$. The complete chloroplast DNA sequences of 13 hexaploid wheat samples were determined: Free-threshing-T. aestivum subsp. aestivum, one sample; T. aestivum subsp. compactum, two samples; T. aestivum subsp. sphaerococcum, one sample; T. aestivum subsp. carthlicoides, four samples. Hulled-T. aestivum subsp. spelta, three samples; T. aestivum subsp. vavilovii jakubz., two samples. The comparative analysis of complete cpDNA sequences of 20 hexaploid wheat samples (13 samples in this article plus 7 samples sequenced in this laboratory in 2018) was carried out. PCR-based haplotype analysis of the fourth intron of Wknox1d and of the fifth-to-sixth exon region of Wknox $1 b$ of all 20 hexaploid wheat samples was carried out. The 20 hexaploid wheat samples (13 samples in this article plus 7 samples in 2018) can be divided into two groups-T. aestivum subsp. spelta, three samples and T. aestivum subsp. vavilovii collected in Armenia, and the remaining 16 samples, including T. aestivum subsp. vavilovii collected in Europe (Sweden). If we take the cpDNA of Chinese Spring as a reference, 25 SNPs can be identified. Furthermore, 13-14 SNPs can be identified in T. aestivum subsp. spelta and subsp. vavilovii (Vav1). In the other samples up to 11 SNPs were detected. 22 SNPs are found in the intergenic regions, 2 found in introns, and 10 SNPs were found in the genes, of which seven are synonymous. PCR-based haplotype analysis of the fourth intron of Wknox $1 d$ and the fifth-to-sixth-exon region of Wknox $1 b$ provides an opportunity to make an assumption that hexaploid wheats T. aestivum subsp. macha var. palaeocolchicum and var. letshckumicum differ from other macha samples by the absence of a $42 \mathrm{bp}$ insertion in the fourth intron of Wknox1d. One possible explanation for this observation would be that two Aegilops tauschii Coss. (A) and (B) participated in the formation of hexaploids through the D genome: Ae. tauschii (A) - macha (1-5, 7, 8, 10-12), and Ae. tauschii (B)-macha M6, M9, T. aestivum subsp. aestivum cv. 'Chinese Spring' and cv. 'Red Doly'.
\end{abstract}

Keywords: Triticum aestivum L.; chloroplast DNA; sequencing; Illumina; SNP; Wknox1 gene

\section{Introduction}

Wheat is the leading grain crop in the world. It originated in the Fertile Crescent approximately 10,000 years ago and has since spread worldwide. There are two biological species of hexaploidy wheat-T. aestivum, genome BBA ${ }^{\mathrm{u}} \mathrm{A}^{\mathrm{u}} \mathrm{DD}$ and Triticum zhukovskyi Menabde \& Ericz., GGA ${ }^{\mathrm{u}} \mathrm{A}^{\mathrm{u}} \mathrm{A}^{\mathrm{m}} \mathrm{A}^{\mathrm{m}}$. T. zhukovskyi and its predecessors (Triticum monococcum L. and Triticum timopheevii (Zhuk.) Zhuk.) form a separate lineage irrelevant to the evolution of the principal wheat lineage, which is formed by T. aestivum and its predecessors Aegilops tauschii Coss. And Triticum turgidum L. [1]. 
The T. aestivum lineage is divided into the domesticated, hulled lineage and the free-threshing lineage. The free-threshing lineage includes T. aestivum subsp. Aestivum, T. aestivum subsp. Compactum (Host) Mackey, T. aestivum subsp. Sphaerococcum (Percival) Mackey, and T. aestivum subsp. carthlicoides nom. nud. (Tables 1 and 2).

Table 1. List of hexaploid wheats.

\begin{tabular}{|c|c|c|c|}
\hline & Species & Genome & Plasmon \\
\hline \multirow{5}{*}{$\begin{array}{c}\begin{array}{c}\text { Hulled } \\
\text { T. zhukovskyi }\end{array} \\
\text { Hulled } \\
\text { T. aestivum }\end{array}$} & & $\mathrm{GGA}^{\mathrm{u}} \mathrm{A}^{\mathrm{u}} \mathrm{A}^{\mathrm{m}} \mathrm{A}^{\mathrm{m}}$ & G \\
\hline & & & \\
\hline & T. aestivum subsp. spelta Thell. & $\mathrm{BBA}^{\mathrm{u}} \mathrm{A}^{\mathrm{u}} \mathrm{DD}$ & $\mathrm{B}$ \\
\hline & $\begin{array}{l}\text { T. aestivum subsp. macha (Dekapr. and } \\
\text { Menabde) Mackey }\end{array}$ & & \\
\hline & T. aestivum subsp. vavilovii Jakubz. & & \\
\hline \multirow[t]{4}{*}{$\begin{array}{l}\text { Free-threshing } \\
\text { T. aestivum }\end{array}$} & T. aestivum subsp. aestivum & & \\
\hline & $\begin{array}{l}\text { T. aestivum subsp. compactum } \\
\text { (Host) Mackey }\end{array}$ & & \\
\hline & $\begin{array}{l}\text { T. aestivum subsp. sphaerococcum } \\
\text { (Percival) Mackey }\end{array}$ & & \\
\hline & $\begin{array}{l}\text { T. aestivum subsp. carthlicoides } \\
\text { nom. nud. }\end{array}$ & & \\
\hline
\end{tabular}

Table 2. Jacubciner's classification system (1958) According to Yen a. Yang [2].

\begin{tabular}{|c|c|c|c|}
\hline Congretio & Species & Distribution Areas & Habits \\
\hline Hexaploidea & Cultivated hulled & & \\
\hline \multirow[t]{8}{*}{$2 n=42$} & T. zhukovskyi Men.et Er. & Georgia & Springness \\
\hline & T. macha Dek.et Men. & Georgia & Winterness \\
\hline & T. spelta L. & Iran, south Germany, Spain & Winterness, Springness \\
\hline & Cultivated naked grain & & \\
\hline & T. aestivum L. & All over the world & Springness, winterness, half winterness \\
\hline & T. compactum Host & $\begin{array}{l}\text { Transcaucasia, Kazakhstan, } \\
\text { Asia Minor, Afghan, Chile }\end{array}$ & Springness, winterness, half-winterness \\
\hline & T. vavilovii Jakubz. & Armenia & Winterness \\
\hline & T. sphaerococcum Perc. & Pakistan, India & Springness \\
\hline
\end{tabular}

Hexaploid wheat T. aestivum subsp. carthlicoides was found by Kuckuck [3] near the border of Turkey, Armenia and West Georgia. This hexaploid wheat showed the subsp. carthlicum-like spike morphology.

The hulled lineage includes spelt wheat T. aestivum subsp. spelta Thell., macha T. aestivum subsp. macha (Dekapr. and Menabde) Mackey and T. aestivum subsp. vavilovii Jakubz. In hulled wheats, glumes tenaciously enclose seeds, and strong mechanical force is needed to liberate seeds from glumes during threshing.

According to Dekaprelevich, Georgia is characterized by the largest number of cultivated wheat species in the world; altogether, 12 species of are found here. Only three narrowly endemic species, Triticum abyssinicum Vav., T. sphaerococcum and T. spelta, are absent [4]. 
South Caucasus (notably Georgia) and its earlier residents played an important role in wheat formation. In total, 17 domesticated species and subspecies of Triticum are known. Georgian endemic wheat species include one Triticum species and four subspecies [5-7]:

1. Triticum turgidum subsp. palaeocolchicum (Menabde) A. Love

2. Triticum turgidum subsp. carthlicum (Nevski) A. Love

3. Triticum timopheevii subsp. zhukovskyi (Menabde \& Ericzjan) L. B. Cai

4. Triticum zhukovskyi Menabde \& Ericzjan

5. Triticum aestivum subsp. macha (Dekapr. \& Menabde) McKey

All these cultivated species and subspecies have been found only in West Georgia, except subsp. carthlicum which has been distributed in East Georgia as well. All these species and subspecies grew in the territory of Georgia until the middle of the last century.

The "Wheat Enigma" was a term for the observation that wild predecessors of five Georgian endemic wheat subspecies are found in Fertile Crescent, quite far from the South Caucasus [8,9]. One possibility to explain the "Wheat Enigma" is that speakers of ProtoGeorgian language could have moved to Mesopotamia after migration from Africa to the Arabian Peninsula, where wheat was domesticated. Furthermore, they could have migrated to South Caucasus together with domesticated wheat subspecies $[9,10]$.

The examination of genealogical data provides insights into the evolutionary history of a species. The wide application of gene genealogies for evolutional studies in plants involves identifying DNA sequences with levels of ordered variation within chloroplast, mitochondrial, or nuclear genomes [11]. Traditionally, extranuclear DNA, such as chloroplast DNA (cpDNA), has been considered as an effective tool for genealogic studies [12-14]. The sequences of wheat plasmons B and G (complete cpDNA sequences) of the genus Triticum were determined in our laboratory $[8,15,16]$. Plasmon B is detected in polyploid species-Triticum turgidum and T. aestivum. Plasmon of T. zhukovskyi belong to the G type.

Another effective tool for gene genealogy studies for Triticum species is the three homoeologous loci of wheat Wknox1 gene, functioning at shoot apical meristems (SAM) [17]. A comparative study of the three Wknox 1 genomic sequences revealed accumulation of numerous mutations, particularly in the fourth intron and the $5^{\prime}$-upstream region. Later, Takumi a. Morimoto [18] reported the discovery of a new allele for the fifth-to-sixth exon region of the Wknox1b KNOTTED1-type homeobox gene in a common wheat subspecies (T. aestivum subsp. carthlicoides).

The purpose of the present investigation was to carry out the comparative analysis of complete cpDNA sequences of 20 hexaploid wheat accessions (T. aestivum subsp. aestivum, two samples; T. aestivum subsp. compactum, two samples; T. aestivum subsp. sphaerococcum, one sample; T. aestivum subsp. carthlikoides, four samples; T. aestivum subsp. spelta, three samples; T. aestivum subsp. macha, six samples; T. aestivum subsp. vavilovii, two samples.

The second aim of the present investigation was to carry out a PCR-based haplotype analysis of the fourth intron of Wknox $1 d$ and of the fifth-to-sixth exon region of Wknox $1 b$ of all 20 hexaploid wheat samples.

\section{Results}

\subsection{Complete cpDNA Sequence of Hexaploid Wheats}

For comparative analysis of chloroplast DNA of hexaploid wheats, 20 hexaploid wheat samples were selected. CpDNA sequences from 13 of them were sequenced in this study, and the remaining 7 were sequenced earlier [15] (Table 3).

The samples were structured as follows: free-threshing-T. aestivum subsp. aestivum, two samples-Chinese Spring and Red Doly; T. aestivum subsp. compactum-two samples; T. aestivum subsp. sphaerococcum - one sample; T. aestivum subsp. carthlicoides-four samples; Hulled-T. aestivum subsp. spelta-three samples; T. aestivum subsp. vavilovii two samples; T. aestivum subsp. macha-six samples.

To illustrate the evolutionary relationship among the studied cultivars, a phylogenetic tree was constructed based on complete nucleotide sequences of cpDNA of 20 hexaploid wheat samples (Figure 1). 
Table 3. Hexaploid wheat accessions used in the study.

\begin{tabular}{|c|c|c|c|}
\hline & Botanical Name & GenBank Accession Number & \\
\hline \multicolumn{4}{|c|}{ Hulled } \\
\hline M1 & $\begin{array}{l}\text { Triticum aestivum L. subsp. macha (Dekapr. and } \\
\text { Menabde) Mackey var. megrelicum (Menabde) }\end{array}$ & LC372826 & ISU \\
\hline M2 & $\begin{array}{l}\text { Triticum aestivum L. subsp. macha (Dekapr. and } \\
\text { Menabde) Mackey var. georgicum (Menabde) }\end{array}$ & LC373211 & ISU \\
\hline M3 & $\begin{array}{l}\text { Triticum aestivum L. subsp. macha (Dekapr. and } \\
\text { Menabde) Mackey var. colchicum (Dekapr. } \\
\text { and Menabde) }\end{array}$ & LC375536 & ISU \\
\hline M4 & $\begin{array}{l}\text { Triticum aestivum L. subsp. macha (Dekapr. and } \\
\text { Menabde) Mackey var. scharaschidzei (Menabde) }\end{array}$ & LC374397 & ISU \\
\hline M5 & $\begin{array}{l}\text { Triticum aestivum L. subsp. macha (Dekapr. and } \\
\text { Menabde) Mackey var. palaeoimereticum (Dekapr. } \\
\text { and Menabde) }\end{array}$ & LC375773 & ISU \\
\hline M6 & $\begin{array}{l}\text { Triticum aestivum L. subsp. macha (Dekapr. and } \\
\text { Menabde) Mackey var. palaeocolchicum (Dekapr. } \\
\text { and Menabde) }\end{array}$ & NC_025955 & ISU \\
\hline M7 & $\begin{array}{l}\text { Triticum aestivum L. subsp. macha (Dekapr. and } \\
\text { Menabde) Mackey var. ericzjanae Menabde }\end{array}$ & & ISU \\
\hline M8 & $\begin{array}{l}\text { Triticum aestivum L. subsp. macha (Dekapr. and } \\
\text { Menabde) Mackey var. ibericum Dekapr. } \\
\text { and Menabde }\end{array}$ & & ISU \\
\hline M9 & $\begin{array}{l}\text { Triticum aestivum L. subsp. macha (Dekapr. and } \\
\text { Menabde) Mackey var. letshchumicum Dekapr. } \\
\text { and Menabde }\end{array}$ & & ISU \\
\hline M10 & $\begin{array}{c}\text { Triticum aestivum L. subsp. macha (Dekapr. and } \\
\text { Menabde) Mackey var. subcolchicum Dekapr. } \\
\text { and Menabde }\end{array}$ & & ISU \\
\hline M11 & $\begin{array}{l}\text { Triticum aestivum L. subsp. macha (Dekapr. and } \\
\text { Menabde) Mackey var. submegrelicum Dekapr. } \\
\text { and Menabde }\end{array}$ & & ISU \\
\hline M12 & $\begin{array}{l}\text { Triticum aestivum L. subsp. macha (Dekapr. and } \\
\text { Menabde) Mackey var. subletshchumicum Dekapr. } \\
\text { and Menabde }\end{array}$ & & ISU \\
\hline Splt2 & Triticum aestivum L. subsp. spelta (L.) Thell. & LC625352 & PI 348000 \\
\hline Splt1 & Triticum aestivum L. subsp. spelta (L.) Thell. & LC625353 & PI 348220 \\
\hline Splt3 & Triticum aestivum L. subsp. spelta (L.) Thell. & LC625866 & PI 191393 \\
\hline Vav1 & Triticum vavilovii Jakubz. & LC621349 & PI 326319 \\
\hline Vav2 & Triticum vavilovii Jakubz. & LC625865 & PI 428342 \\
\hline \multicolumn{4}{|c|}{ Free-threshing } \\
\hline $\mathrm{RD}$ & $\begin{array}{l}\text { Triticum aestivum L. subsp. aestivum var. } \\
\text { ferrugineum (Alef.) Mansf. cv. 'Red Doly' }\end{array}$ & LC377169 & ISU \\
\hline CS & $\begin{array}{l}\text { Triticum aestivum L. subsp. aestioum cv. } \\
\text { 'Chinese Spring' }\end{array}$ & LC622404 & \\
\hline Cc1 & Triticum aestivum L. subsp. carthlicoides nom. nud. & LC621350 & PI 262678 \\
\hline $\mathrm{Cc} 3$ & Triticum aestivum L. subsp. carthlicoides nom. nud. & LC621195 & SRCA \\
\hline
\end{tabular}


Table 3. Cont.

\begin{tabular}{|c|c|c|c|}
\hline & Botanical Name & GenBank Accession Number & \\
\hline \multicolumn{4}{|c|}{ Hulled } \\
\hline $\mathrm{Cc} 2$ & Triticum aestivum L. subsp. carthlicoides nom. nud. & LC622405 & PI 532901 \\
\hline Cc4 & Triticum aestivum L. subsp. carthlicoides nom. nud. & LC621194 & SRCA \\
\hline Com2 & $\begin{array}{l}\text { Triticum aestivum L. subsp. compactum } \\
\text { (Host) Mackey }\end{array}$ & LC623766 & KU-9873 \\
\hline Com1 & $\begin{array}{l}\text { Triticum aestivum L. subsp. compactum } \\
\text { (Host) Mackey }\end{array}$ & LC623764 & ISU \\
\hline Sph1 & $\begin{array}{l}\text { Triticum aestivum L. subsp. sphaerococcum } \\
\text { (Percival) Mackey }\end{array}$ & LC623765 & Cltr17737 \\
\hline
\end{tabular}

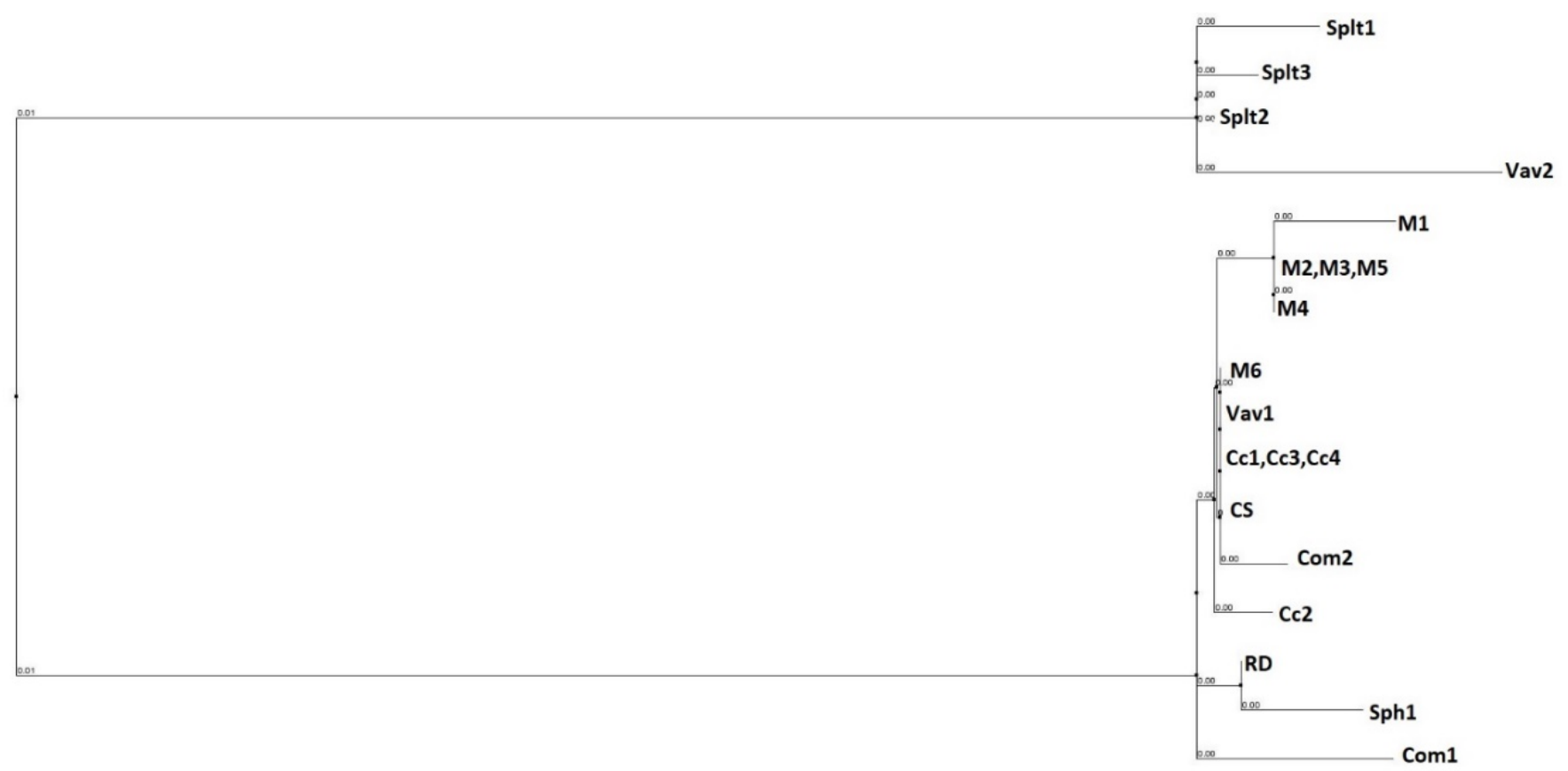

Figure 1. Complete chloroplast genome phylogeny of hexaploid wheats.

If we take the cpDNA of Chinese Spring as a reference, 25 SNPs can be identified. Furthermore, 13-14 SNPs can be identified in T. aestivum subsp. Spelta and subsp. Vavilovii (Vav1) (collected in Armenia) (Table 4). In the other samples, up to 11 SNPs were detected. In total, 22 SNPs are found in the intergenic regions, 2 were found in introns, and 10 SNPs were found in the genes, of which seven are synonymous and do not alter the amino acids. Indels specific for $20 \mathrm{cpDNA}$ are given in Table 5 .

One 35bp insertion and three inversions (56bp, 58bp and 25bp in length) have been identified in Triticum aestivum subsp. spelta (Splt1, Splt2, Splt3) and T. aestivum subsp. vavilovii (Vav2) samples (Table 6). One 38bp inversion (TCGGCTCAATCTTTTTTTTCTAAAAAAGATTGAGCCGA) with a $4 \mathrm{bp}$ loop has been identified in T. aestivum subsp. vavilovii (Vav1) (collected in Armenia) in the position 56,120-56,157 (intergenic rbcL_psaI).

This section may be divided into subheadings. It should provide a concise and precise description of the experimental results, their interpretation, as well as the experimental conclusions that can be drawn. 
Table 4. SNPs specific for chloroplast DNA of hexaploid wheats.




Table 4. Cont.

\begin{tabular}{|c|c|c|c|c|c|c|c|c|c|c|c|c|c|c|c|c|c|c|}
\hline $\begin{array}{l}\text { Nucleotide } \\
\text { Position } \\
\text { According to CS }\end{array}$ & Locus & CS & M6 & Vav1 & Cc2 & $\begin{array}{l}\text { Cc1, } \\
\text { Cc3, } \\
\text { Cc4 }\end{array}$ & RD & Sph1 & $\begin{array}{l}\text { M2, } \\
\text { M3, } \\
\text { M5 }\end{array}$ & M4 & M1 & Com1 & Com2 & Splt1 & Splt2 & Splt3 & Vav2 & $\begin{array}{l}\text { Amino Acid } \\
\text { Substitution }\end{array}$ \\
\hline 64,318 & Intergenic $p$ saJ-rpl33 & $\mathrm{C}$ & & & & & & & & & & & & $\mathrm{T}$ & $\mathrm{T}$ & $\mathrm{T}$ & $\mathrm{T}$ & \\
\hline 73,742 & Intergenic petD-rpoA & $\mathrm{T}$ & & & & & & & & & & & & $\mathrm{C}$ & $\mathrm{C}$ & $\mathrm{C}$ & $\mathrm{C}$ & \\
\hline 78,113 & Intron $r p l 16$ & $\mathrm{C}$ & & & & & & & & & & & & $\mathrm{T}$ & $\mathrm{T}$ & $\mathrm{T}$ & $\mathrm{T}$ & \\
\hline 78,732 & Intergenic $r p l 16-r p s 3$ & G & & & & & & & & & & & & $\mathrm{T}$ & $\mathrm{T}$ & $\mathrm{T}$ & $\mathrm{T}$ & \\
\hline 100,961 & Gene $r p s 15$ & $\mathrm{~T}$ & & & & & & & & & G & & & & & & & Syn \\
\hline 102,561 & Gene $n d h F$ & $\mathrm{C}$ & & & & & & & $\mathrm{T}$ & $\mathrm{T}$ & $\mathrm{T}$ & & & & & & & Syn \\
\hline 104,993 & $\begin{array}{c}\text { Intergenic } \\
\text { rpl32-trnL-TAG }\end{array}$ & A & & & & & & & & & & & & $\mathrm{C}$ & $\mathrm{C}$ & $\mathrm{C}$ & C & \\
\hline 105,477 & $\begin{array}{c}\text { Intergenic } \\
\text { rpl32-trnL-TAG }\end{array}$ & $\mathrm{C}$ & & & & & & & & & & & & A & A & $\mathrm{A}$ & A & \\
\hline 106,672 & Gene $\operatorname{ccs} A$ & $\mathrm{C}$ & & & & & & & & & & & & $\mathrm{T}$ & $\mathrm{T}$ & $\mathrm{T}$ & $\mathrm{T}$ & Syn \\
\hline 114,943 & Gene $r p s 15$ & $\mathrm{~A}$ & & & & & & & & & $\mathrm{C}$ & & & & & & & F-L \\
\hline 133,405 & $\begin{array}{c}\text { Intergenic } \\
\text { trnI-CAT-rpl23 }\end{array}$ & A & & & & & & & & & & $\mathrm{C}$ & & & & & & \\
\hline
\end{tabular}

Table 5. Indels specific for chloroplast DNA of hexaploid wheats.

\begin{tabular}{|c|c|c|c|c|c|c|c|c|c|c|c|c|c|c|c|c|c|}
\hline $\begin{array}{c}\text { Nucleotide } \\
\text { Position } \\
\text { According to CS }\end{array}$ & Locus & CS & M6 & Vav1 & Cc2 & $\begin{array}{l}\mathrm{Cc} 1, \\
\mathrm{Cc} 3, \\
\mathrm{Cc} 4\end{array}$ & RD & Sph1 & $\begin{array}{l}\text { M2, } \\
\text { M3, } \\
\text { M5 }\end{array}$ & M4 & M1 & Com2 & Com1 & Splt1 & Splt2 & Splt3 & Vav2 \\
\hline 4175 & $\begin{array}{l}\text { Intergenic } \\
\text { matK-rps16 }\end{array}$ & - & & & & & & & & & & & & AAAAT & AAAAT & AAAAT & AAAAT \\
\hline 7422 & $\begin{array}{c}\text { Intergenic } \\
\text { psbI-trnS-GCT }\end{array}$ & $15 \mathrm{~T}$ & & & & & & & & & & & & $18 \mathrm{~T}$ & $12 \mathrm{~T}$ & $12 \mathrm{~T}$ & $12 \mathrm{~T}$ \\
\hline 8219 & $\begin{array}{c}\text { Intergenic } \\
\text { trnS-GCT-psbD }\end{array}$ & $10 \mathrm{~T}$ & & & & & $11 \mathrm{~T}$ & & & & & & & & & & \\
\hline
\end{tabular}


Table 5. Cont.




Table 5. Cont.

\begin{tabular}{|c|c|c|c|c|c|c|c|c|c|c|c|c|c|c|c|c|c|}
\hline $\begin{array}{c}\text { Nucleotide } \\
\text { Position } \\
\text { According to CS }\end{array}$ & Locus & CS & M6 & Vav1 & Cc2 & $\begin{array}{l}\text { Cc1, } \\
\text { Cc3, } \\
\text { Cc4 }\end{array}$ & RD & Sph1 & $\begin{array}{l}\text { M2, } \\
\text { M3, } \\
\text { M5 }\end{array}$ & M4 & M1 & Com2 & Com1 & Splt1 & Splt2 & Splt3 & Vav2 \\
\hline 77,140 & Intergenic rpl14-rpl16 & $10 \mathrm{~T}$ & & & & & & & & & & & $9 \mathrm{~T}$ & $9 \mathrm{~T}$ & $9 \mathrm{~T}$ & $9 \mathrm{~T}$ & $9 \mathrm{~T}$ \\
\hline 104,113 & Intergenic ndhF-rpl32 & $13 \mathrm{~A}$ & & & & & & & & & & & & $11 \mathrm{~A}$ & $12 \mathrm{~A}$ & $14 \mathrm{~A}$ & \\
\hline 129,319 & IntronndhB & $5 \mathrm{~A}$ & & & & & & & & & & & & & & & $4 \mathrm{~A}$ \\
\hline
\end{tabular}

Table 6. Inversions and a long insertion specific for chloroplast DNA of hexaploid wheats.

\begin{tabular}{|c|c|c|c|c|}
\hline $\begin{array}{l}\text { Nucleotide Position } \\
\text { According to CS }\end{array}$ & Locus & Splt1, Splt2, Splt3, Vav2 & & Length \\
\hline 79,532 & Gene $r p l 22$ & GATGGATCTAAAGGTTATTTAGATTTCTTTACTAT & Insertion & $35 \mathrm{bp}$ \\
\hline $105,139-105,196$ & Intergenic $r p l 32$ - $r n L-T A G$ & $\begin{array}{l}\text { ACTTTTCATAATTTTCATAATAGAATCCT } \\
\text { CATATTTTATTATGAAAATTATGAAAAGT }\end{array}$ & Inversion with $14 \mathrm{bp}$ loop & $58 \mathrm{bp}$ \\
\hline $106,795-106,819$ & Intergenic $\operatorname{css} A-n d h D$ & AAAACCTTCATGAAATGAAGGTTTT & Inversion with 3 bp loop & $25 \mathrm{bp}$ \\
\hline $135,896-52$ & Intergenic $r p s 19-p s b A$ & $\begin{array}{l}\text { AAAGACAGAAATACCCAATATCTTGCTA } \\
\text { GAACAAGATATTGGGTATTTCTGTCTTT }\end{array}$ & Inversion with 6 bp loop & $56 \mathrm{bp}$ \\
\hline
\end{tabular}




\subsection{PCR Analysis of Three Homoeologous Loci of Wheat Wknox1 Gene}

\subsubsection{Wknox1d Fourth Intron Region}

In the present investigation, the genomic sequences of the Wknox $1 d$ fourth intron regions were amplified by PCR using the primer pair of Takumi a. Morimoto [18] (Table 7). A common wheat, T. aestivum subsp. aestivum cv. 'Chinese Spring' (CS), and a durum wheat, T. turgidum subsp. durum cv. 'Langdon' (Ldn), were used for PCR as control and the amplified DNA fragments were visualized on an agarose gel. In the fourth intron of Wknox1d in common wheat, a 122-bp MITE insertion has been reported [17]. The MITEcontaining band (411 bp) was missing in all tetraploid wheat accessions and was observed in all subspecies of common wheat. In the case of subsp. macha (11 samples) the $453 \mathrm{bp}$ band was observed. In the case of two macha samples (M6 and M9) the MITE-containing band typical for other hexaploid subspecies (411 bp) were detected.

Table 7. PCR-based haplotype analysis of the fourth intron of Wknox1d. A 122-bp MITE insertion specifically observed at the D-genome locus of Wknox1 generates the upper bands (411 bp) in hexaploid wheat accessions (except Triticum aestivum L. subsp. compactum) and $453 \mathrm{bp}$ in macha accessions.

\begin{tabular}{|c|c|c|c|c|c|}
\hline Sample & PCR Product, bp & & & & \\
\hline & 277,284 & 375 & 400 & 411 & 453 \\
\hline Triticum aestivum subsp.aestivum cv. 'Chinese Spring' (CS) & + & + & & + & \\
\hline $\begin{array}{l}\text { Triticum aestivum subsp. aestivum var. ferrugineum (Alef.) Mansf. } \\
\text { cv. 'Red Doly' (RD) }\end{array}$ & + & + & & + & \\
\hline Triticum aestivum subsp. carthlicoides (Cc1, Cc2. Cc3. Cc4) & + & + & & + & \\
\hline Triticum aestivum subsp. compactum (Com2) & + & & & & \\
\hline Triticum aestivum subsp. compactum (Com1) & + & + & & + & \\
\hline Triticum aestivum subsp. sphaerococcum (Sph1) & + & + & & + & \\
\hline Triticum aestivum subsp. macha (M6, M9) & + & + & & + & \\
\hline $\begin{array}{l}\text { Triticum aestivum subsp. macha (M1, M2, M3, M4, M5, M7, M8 } \\
\text { M10, M11, M12) }\end{array}$ & + & & + & & + \\
\hline Triticum aestivum subsp. spelta (splt1, splt2, splt3) & + & + & & + & \\
\hline Triticum vavilovii (Arm) (Vav1) & + & + & & + & \\
\hline Triticum vavilovii (Eur) (Vav2) & + & + & & + & \\
\hline Triticum turgidum subsp. carthlicum var. rubiginosum & + & & & & \\
\hline Triticum turgidum subsp. durum cv. 'Langdon' (Ldn) & + & & & & \\
\hline
\end{tabular}

In $2 \%$ agarose-gel, the PCR-amplified, fourth intron of the Wknox1d DNA region of hexaploid wheat gives four bands: N1 (280 bp), N2 (375 bp), N3 (411 bp), and N4 (453). Bands N3 and N4 were cut out and sequenced. In the case of band N4 (453), a 42 bp insertion was detected in the position 7009-AGTTTGCACACCTGAACATTTTGCATTATGTTCGGGAGCCTA (Figure 2).

\subsubsection{Fifth-to-Sixth Exon Region of Wknox $1 b$}

PCR-based haplotype analysis of the fifth-to-sixth exon region of Wknox $1 b$ showed that the 157-bp MITE inserted band (588 bp) is present in T. turgidum subsp. durum $\mathrm{cv}$. 'Langdon'; CS; Red Doly (Table 8). This band is absent in tetraploid T. turgidum subsp. carthlicum, T. aestivum L. subsp. carthlicoides, T. aestivum subsp. macha (M1-M13).

Hexaploid wheats with matching values of the fourth intron of Wknox $1 d$ and the fifth-to-sixth-exon region of $W k n o x 1 b$ are given in Table 9. 


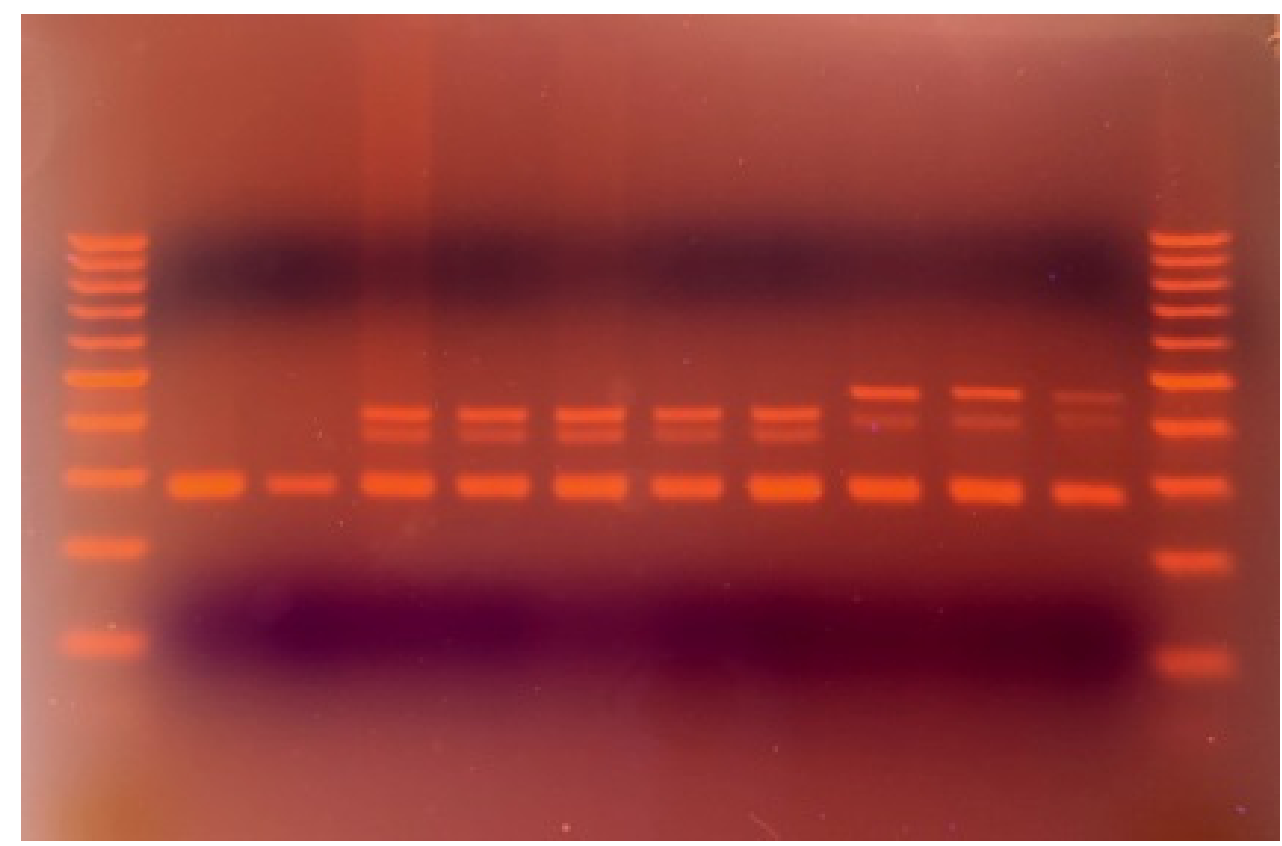

Figure 2. Image of $2 \%$ agarose gel electrophoresis of PCR-amplified fourth intron of Wknox1d DNA region of hexaploid wheat. Lanes: 2-T. turgidum subsp. carthlicum, 3-T. turgidum subsp. durum (Ldn), 4-T. aestivum subsp. aestivum (CS), 5-T. aestivum subsp. carthlicoides, 6-T. aestivum subsp. carthlicoides, 7-T. aestivum subsp. macha (M_6), 8-T. aestivum subsp. macha (M_9), 9-T. aestivum subsp. macha (M_1), 10-T. aestivum subsp. macha (M_2), 11-T. aestivum subsp. macha (M_3); Lanes $1,12-100$ bp DNA marker.

Table 8. PCR-based haplotype analysis of the fifth-to-sixth exon region of Wknox $1 b$.

\begin{tabular}{|c|c|c|c|c|}
\hline \multirow[t]{2}{*}{ Sample } & \multicolumn{4}{|c|}{ PCR Product, bp } \\
\hline & 410 & 429,430 & 560 & 588 \\
\hline Triticum aestivum subsp.aestivum cv. 'Chinese Spring' (CS) & & + & + & + \\
\hline $\begin{array}{l}\text { Triticum aestivum subsp. aestivum var. ferrugineum cv. 'Red } \\
\text { Doly' (RD) }\end{array}$ & & + & + & + \\
\hline Triticum aestivum subsp. carthlicoides (Cc1, Cc2, Cc3, Cc4) & & + & & \\
\hline Triticum aestivum subsp. compactum (Com2) & & + & + & + \\
\hline Triticum aestivum subsp. compactum (Com1) & & + & & \\
\hline Triticum aestivum subsp. sphaerococcum (Sph1) & & + & + & + \\
\hline Triticum aestivum subsp. macha (M6, M9) & & + & & \\
\hline $\begin{array}{l}\text { Triticum aestivum subsp. macha (M1, M2, M3, M4, M5, M7, M } \\
\text { 8, M10, M11, M12) }\end{array}$ & & + & & \\
\hline Triticum aestivum subsp. spelta (splt1, splt2, splt3) & & + & + & + \\
\hline Triticum vavilovii (Arm) (Vav1) & + & + & & \\
\hline Triticum vavilovii (Eur) (Vav2) & & + & + & + \\
\hline Triticum turgidum subsp. carthlicum var. rubiginosum & & + & & \\
\hline Triticum turgidum subsp. durum cv. 'Langdon' (Ldn) & & + & + & + \\
\hline
\end{tabular}


Table 9. Hexaploid wheats with matching values of fourth intron of Wknox1d and fifth-to-sixth exon region of Wknox $1 b$.

\begin{tabular}{c}
\hline Triticum aestivum subsp. carthlicoides (Cc1, Cc2, Cc3, Cc4) \\
Triticum aestivum subsp. compactum (Host) (Com1) \\
Triticum aestivum subsp. macha (M6, M9) \\
Triticum vavilovii (Arm) (Vav1)
\end{tabular}

\section{Discussion}

It is widely believed that the birthplace of T. aestivum is in a region between Transcaucasia and southwestern Caspian Iran [19]. The first step in the evolution of cultivated wheat was the formation in northern Mesopotamia of a tetraploid species with an $\mathrm{A}^{\mathrm{u}} \mathrm{A}^{\mathrm{u}} \mathrm{BB}$ genome [20]. Approximately 7000 years ago, the hexaploid bread wheat T. aestivum L. (BBA $\left.{ }^{\mathrm{u}} \mathrm{A}^{\mathrm{u}} \mathrm{DD}\right)$ arose in southwestern Caspian Iran and Transcaucasia by allopolyploidization of the cultivated Emmer wheat Triticum dicoccum Schrank with the Caucasian Ae. tauschii [19,21-24].

It should be noted that Ae. tauschii was found in the western Caucasus as well $[25,26]$. According to authors "Ae. squarrosa (Ae. tauschii) grows in lowlands and mountain foothills, rarely in dry and humid silty areas up to the middle of the mountain, mainly in desert, semi-desert and field vegetation, as well as weeds in Abkhazia, Samegrelo, Imereti, Guria, Adjara, Kartli, in outer Kakheti, Gardabani" [25]. It can be assumed that two Ae. tauschii (A) and (B) participated in the formation of hexaploids through the D genome: Ae. tauschii (A)macha (1-5, 7, 8, 10-12) —and Ae. tauschii (B)—macha M6, M9, CS, RD (Tables 3 and 7).

T. aestivum subsp. catrhlicoides most likely originated in western Transcaucasia [3]; In 1967 Kuckuck had found populations with carthlicium and carthlicoides types near the border of East Turkey (Ardahan and Kars Provinces, Turkey) and West Georgia. This hexaploid wheat accession showed the subsp. carthlicum-like morphology. Subsp. carthlicum was proposed to have originated from spontaneous hybridization between subsp. carthlicoides and cultivated emmer wheat, T. turgidum subsp. dicoccon (Schrank) Thell. Subsp. carthlicoides should be considered as the original and elder genotype from which genes for this particular morphology of the ear were transferred together with the Q-factor to T. carthlicum $[3,18]$. According to Kuckuck, this region was distinguished by a tremendous genetic variation in wheat including T. dicoccum, T. carthlicum and T. aestivum subsp. macha [3]. It can be assumed that subsp. carthlicoides took part in the formation of the subsp. macha as an ancestor.

One of the four subspecies of wheat detected in Georgia is hexaploid, domesticated, hulled wheat T. aestivum subsp. macha [15]. This subspecies was detected in West Georgia in 1928 and described by Dekaprelevich and Menabde [27]. It is endemic to Georgia and is cultivated along with tetraploid West Georgian wheat (T. turgidum subsp. palaeocolchicum) [28].

It is proposed that macha and West Georgian wheats are sibling cultivars that arose in a hybrid swarm involving T. aestivum and wild emmer wheat [29]. It is accepted that spelt wheat is derived from free-threshing hexaploid wheat (T. aestivum subsp. aestivum) by hybridization with hulled emmer (T. turgidum). Experimental data suggest that European and Asian spelt may be polyphyletic. Free-threshing, hexaploid wheat seems to precede spelt. At least some European spelt originated from hybridization of club wheat (T. aestivum subsp. compactum) with emmer (domesticated hulled Triticum turgidum). Free-threshing hexaploid wheat was an ancestor of not only European spelt but also of some of the Asian forms of spelt, although the exact role free-threshing wheat has played is debatable [1].

The comparative analysis of complete nucleotide sequence 20 samples of hexaploid wheats offers the opportunity to draw several conclusions: 20 hexaploid wheat samples are divided into two groups-Triticum aestivum subsp. spelta three samples + T. aestivum subsp. vavilovii (Vav1) (collected in Armenia), and the remaining 16 samples including T. aestivum subsp. vavilovii (Vav2) (Collected in Sweden).

Hirosawa et al. [30] found two cpDNA SSR lineages in T. aestivum: Plastogroup I and II. Most subsp. aestivum, compactum, macha, and sphaerococcum accessions belonged to Plas- 
togroup I. Subspecies spelta was split into Plastogroup I (70\% of accessions examined) and Plastogroup II (30\%). So, given the numbers of subsp. spelta accessions used (27 accessions in Hirosawa et al. and 3 in our work), the cpDNA trees (Hirosawa et al.'s and ours) appear quite consistent. Plastogroup I (and our major lineage) might represent a major lineage that was transmitted from cultivated T. turgidum via hybrid cross with Ae. tauschii and its subsequent allopolyploidization. Plastogroup II (and our minor lineage) might have resulted from introgression between hexaploid and tetraploid wheats, because subsp. spelta has the emmer wheat ancestry in Europe and Asia [1].

PCR-based haplotype analysis of the fourth intron of Wknox1d and the fifth-to-sixthexon region of $W k n o x 1 b$ of all 20 hexaploid wheat samples was carried out. PCR-based haplotype analysis of the fourth intron of Wknox1d and the fifth-to-sixth-exon region of Wknox $1 b$ provides an opportunity to make an assumption that hexaploid wheats T. aestivum subsp. macha var. palaeocolchicum and var. letshckumicum differ from other macha samples by the absence of a $42 \mathrm{bp}$ insertion in the fourth intron of Wknox1d. It can be assumed that two Ae. tauschii (A) and (B) participated in the formation of hexaploids through the D genome: Ae. tauschii (A) - macha (1-5, 7, 8, 10-12)-and Ae. tauschii (B)-macha M6, M9, T. aestivum subsp. aestivum cv. 'Chinese Spring' and cv. 'Red Doly'. Another possible explanation would be that the insertion might have arisen during the diversification process of common wheat after polyploidization.

In recent years, wheat yields have not increased per hectare, which is important due to the growing world population. Transferring agronomically important genes from wild relatives to common wheat has been shown to be an effective genetic resource for hexaploid wheat improvement. Advances in new technologies have made the complete wheat reference genome available, which offers a promising future for the study of wheat improvement which is essential to meet global food demand [31].

\section{Materials and Methods}

4.1. Plant Material, DNA Isolation, PCR Analysis, Genomic DNA Library Preparation and Sequencing on an Illumina NovaSeq 6000 Platform

The seeds of hexaploid wheat samples were received from the seed bank of The Agricultural University of Georgia (the late Prof. P. Naskidashvili) and Institute of Botany (Ilia State University, Tbilisi, Georgia) (ISU); The U.S. National Plant Germplasm System (GRINGlobal); The National BioResource Project-WHEAT Centre (Graduate School of Agriculture, Kyoto University, Kyoto, Japan); The Scientific Research Center of Agriculture (SRCA) (Georgia) and Tel Aviv University (Israel). The seeds were germinated in water at room temperature. Total genomic DNA extraction from young leaves, the construction of genomic DNA libraries and assembly of cpDNA have been described earlier [15,31]. An automatic annotation of cpDNA was performed by CpGAVAS [32]. For detection of SNPs (single nucleotide polymorphism) and Indels (insertion/deletion) and phylogeny tree construction, computer programs Mafft and Blast were used [33,34].

\subsection{Construction of Shotgun Genomic DNA Libraries}

Construction of 13 shotgun genomic libraries and sequencing on the NovaSeq 6000 was carried out at the Roy J. Carver Biotechnology Center, University of Illinois at UrbanaChampaign (UIUC). The shotgun genomic DNA libraries were constructed from 50 ng of DNA after sonication with a Covaris ME220 (Covaris, MA, USA) to an average fragment size of $400 \mathrm{bp}$ with the Hyper Library Preparation Kit from Kapa Biosystems (Roche, CA, USA). To prevent index switching, the libraries were constructed using unique dual-indexed adaptors from Illumina (San Diego, CA, USA). The individually barcoded libraries were amplified with 6 cycles of PCR and run on a Fragment Analyzer (Agilent, CA, USA) to confirm the absence of free primers and primer dimers and to confirm the presence of DNA of the expected size range. Libraries were pooled in equimolar concentration and the pool was further quantitated by qPCR on a BioRad CFX Connect Real-Time System (Bio-Rad Laboratories, Inc., Hercules, CA, USA). 


\subsection{Sequencing of Libraries in the NovaSeq}

The pooled, barcoded, shotgun libraries were loaded on a NovaSeq SP lane for cluster formation and were sequenced for 150 cycles from each side of the DNA fragments. The fastq read files were generated and demultiplexed with the bcl2fastq v2.20 Conversion Software (Illumina, San Diego, CA, USA).

\subsection{PCR Analysis of Three Homoeologous Wheat Wknox1 Gene}

The genomic sequences of the Wknox1d 4th intron regions were amplified by PCR using the primer pair of Takumi a. Morimoto [18]: 5'-AAAAAAAAGGTTAAATGGAC$3^{\prime}$ and $5^{\prime}$-ACCTTATACATGATTGGGAA- $3^{\prime}$. The Wknox $1 b$ 5th-to-6th exon region was amplified by PCR using the primer pair $5^{\prime}$-GCTGAAGCACCATCTCCTGA- $3^{\prime}$ and $5^{\prime}-$ CATGTAGAAGGCGGCGTTAG-3'. The DNA fragments (PCR products) were excised from the agarose gel. The DNA extraction and purification from the agarose gel was performed by the QIAquick Gel Extraction Kit (QIAGEN). PCR products were purified with GenElute PCR Clean-Up Kit (Sigma-Aldrich), dye labeled using a Big Dye Terminator Kit (Applied Biosystems), and sequenced on Applied Biosystems 3700 genetic analyzer (Laboratory Services Division of the University of Guelph, Guelph, ON, Canada).

\section{Conclusions}

Based on complete chloroplast DNA sequences, the 20 hexaploid wheat samples can be divided into two groups-T. aestivum subsp. spelta three samples $+T$. aestivum subsp. vavilovii collected in Armenia, and the remaining 16 samples, including T. aestivum subsp. vavilovii collected in Europe (Sweden).

Based on the fourth intron of Wknox1d and the fifth-to-sixth-exon region of Wknox1b hexaploid wheats, T. aestivum subsp. macha var. palaeocolchicum and var. letshckumicum were found to differ from other macha samples by the absence of a $42 \mathrm{bp}$ insertion in the fourth intron of Wknox1d.

Two Aegilops tauschii Coss. (A) and (B) participated in the formation of hexaploids through the D genome: Ae. tauschii (A) - macha (1-5, 7, 8, 10-12) -and Ae. tauschii (B)—macha M6, M9, T. aestivum subsp. aestivum cv. 'Chinese Spring' and cv. 'Red Doly'.

Author Contributions: Conceptualization, T.B. and Y.M.; Methodology, M.G.; Software, M.G.; Formal analysis, M.G. and T.B.; Investigation, T.B. and Y.M.; Data curation, M.G., T.B. and Y.M.; Writingoriginal draft preparation, T.B. and M.G.; Writing-review and editing, T.B. and Y.M.; Visualization, M.G. and T.B.; Supervision, T.B.; Project administration, M.G.; Funding acquisition, M.G. All authors have read and agreed to the published version of the manuscript.

Funding: This project was funded by a grant from the Shota Rustaveli National Science Foundation of Georgia (SRNSFG) (grant number: NFR-18-7262).

Institutional Review Board Statement: Not applicable.

Informed Consent Statement: Not applicable.

Data Availability Statement: The complete chloroplast DNA sequence data supporting this study are openly available in GenBank at https: / www.ncbi.nlm.nih.gov/nuccore/LC625352,LC625353,LC625866, LC621349,LC625865,LC377169,LC622404,LC623765,LC621350,LC623764,LC621194,LC622405,LC623766 (accessed on 8 April 2021).

Conflicts of Interest: The authors declare no conflict of interest.

\section{References}

1. Dvorak, J.; Deal, K.R.; Luo, M.-C.; You, F.M.; Von Borstel, K.; Denghani, H. The Origin of Spelt and Free-Threshing Hexaploid Wheat. J. Hered. 2012, 103, 426-441. [CrossRef]

2. Yen, C.; Yang, J. Biosystematics of Triticeae: Volume I. Triticum-Aegilops Complex; Springer Nature: Basingstoke, UK, 2020; Available online: https: / link.springer.com/book/10.1007/978-981-13-9931-2 (accessed on 5 November 2021).

3. Kuckuck, H. On the origin of Triticum carthlicum Nevski (Triticum persicum Vav.). Wheat Inf. Serv. 1979, 50, 1-5.

4. Dekaprelevich, L.L. The role of Georgia in the origin of wheat. Soobsch. Akad. Nauk Gruz. SSR 1941, 2, 915-922. 
5. Menabde, V.L. Wheats of Georgia. Edition of Academy of Science of Georgian SSR; Georgian Academy of Sciences Press: Tbilisi, Georgia, 1948; 272p. (In Russian)

6. Menabde, V.L. Cultivated flora of Georgia. In Botanical Excursions over Georgia; Sakhokia, M.F., Ed.; Publishing House of the Academy of Sciences of Georgian SSR: Tbilisi, Georgia, 1961; pp. 69-76. (In Russian)

7. Hammer, K.; Filatenko, A.A.; Pistrick, K. Taxonomic remarks on Triticum L. and $\times$ Triticosecale Wittm. Genet. Resour. Crop Evol. 2011, 58, 3-10. [CrossRef]

8. Gogniashvili, M.; Naskidashvili, P.; Bedoshvili, D.; Kotorashvili, A.; Kotaria, N.; Beridze, T. Complete chloroplast DNA sequences of Zanduri wheat (Triticum spp.). Genet. Resour. Crop Evol. 2015, 62, 1269-1277. [CrossRef]

9. Beridze, T. The 'Wheat Puzzle' and Kartvelians route to the Caucasus. Genet. Resour. Crop Evol. 2019, 66, 921-927. [CrossRef]

10. Pagel, M.; Atkinson, Q.D.; Calude, A.S.; Meade, A. Ultraconserved words point to deep language ancestry across Eurasia. Proc. Natl. Acad. Sci. USA 2013, 110, 8471-8476. [CrossRef] [PubMed]

11. Schaal, B.A.; Olsen, K.M. Gene genealogies and population variation in plants. Proc. Natl. Acad. Sci. USA 2000, 97, 7024-7029. [CrossRef]

12. Yamane, K.; Kawahara, T. Intra- and interspecific phylogenetic relationships among diploid Triticum-Aegilops species (Poaceae) based on base-pair substitutions, indels, and microsatellites in chloroplast noncoding sequences. Am. J. Bot. 2005, 92, 1887-1898. [CrossRef]

13. Matsuoka, Y.; Mori, N.; Kawahara, T. Genealogical use of chloroplast DNA variation for intraspecific studies of Aegilops tauschii Coss. Theor. Appl. Genet. 2005, 111, 265-271. [CrossRef]

14. Tabidze, V.; Baramidze, G.; Pipia, I.; Gogniashvili, M.; Ujmajuridze, L.; Beridze, T.; Hernandez, A.G.; Schaal, B. The complete chloroplast DNA sequence of eleven grape cultivars. Simultaneous resequencing methodology. J. Int. Sci. Vigne Vin 2014, 48, 99-109. [CrossRef]

15. Gogniashvili, M.; Maisaia, I.; Kotorashvili, A.; Kotaria, N.; Beridze, T. Complete chloroplast DNA sequences of Georgian indigenous polyploid wheats and B plasmon evolution. Genet. Resour. Crop Evol. 2018, 65, 1995-2002. [CrossRef]

16. Gogniashvili, M.; Jinjikhadze, T.; Maisaia, I.; Akhalkatsi, M.; Kotorashvili, A.; Kotaria, N.; Beridze, T.; Dudnikov, A.Y. Complete chloroplast genomes of Aegilops tauschii Coss. and Ae.cylindrica Host sheds light on plasmon D evolution. Curr. Genet. 2016, 62, 791-798. [CrossRef]

17. Morimoto, R.; Kosugi, T.; Nakamura, C.; Takumi, S. Intragenic diversity and functional conservation of the three homoeologous loci of the KN1-type homeobox gene Wknox1 in common wheat. Plant Mol. Biol. 2005, 57, 907-924. [CrossRef]

18. Takumi, S.; Morimoto, R. Implications of an inverted duplication in the wheat KN1-type homeobox gene Wknox 1 for the origin of Persian wheat. Genes Genet. Syst. 2015, 90, 115-120. [CrossRef]

19. Dvorak, J.; Luo, M.C.; Yang, Z.L.; Zhang, H.B. The structure of the Aegilops tauschii genepool and the evolution of hexaploid wheat. Theor. Appl. Genet. 1998, 97, 657-670. [CrossRef]

20. Schneider, A.; Molnar, I.; Molnar-Lang, M. Utilisation of Aegilops (goatgrass) species to widen the genetic diversity of cultivated wheat. Euphytica 2008, 163, 1-19. [CrossRef]

21. Dubcovsky, J.; Dvorak, J. Genome plasticity a key factor in the success of polyploidy wheat under domestication. Science 2007, 316, 1862-1866. [CrossRef] [PubMed]

22. Wang, J.; Luo, M.-C.; Chen, Z.; You, F.M.; Wei, Y.; Zheng, Y.; Dvorak, J. Aegilops tauschii single nucleotide polymorphisms shed light on the origins of wheat D-genome genetic diversity and pinpoint the geographic origin of hexaploid wheat. New Phytol. 2013, 198, 925-937. [CrossRef]

23. Jorgensen, C.; Luo, M.-C.; Ramasamy, R.; Dawson, M.; Gill, B.S.; Korol, A.B.; Distelfeld, A.; Dvorak, J. A high-density genetic map of wild emmer wheat from the Karaca Dağ region provides new evidence on the structure and evolution of wheat chromosomes. Front. Plant Sci. 2017, 8, 1798. [CrossRef]

24. Allaby, R.G.; Stevens, C.; Lucas, L.; Maeda, O.; Fuller, D.Q. Geographic mosaics and changing rates of cereal domestication. Philos. Trans. R. Soc. B 2017, 372, 20160429. [CrossRef]

25. Ketskhoveli, N. Plant guide book of Georgia. Metsniereba Edition; Metsniereba: Tbilisi, Georgia, 1969; Volume 2, p. 481.

26. Kolakovskii, A. Flora of Abkhazia. Metsniereba Edition; Metsniereba: Tbilisi, Georgia, 1986; p. 164.

27. Dekaprelevich, L.L.; Menabde, V.L. Spelt wheats of Western Georgia (Western Transcaucasia). Bull. Appl. Bot. Leningrad. 1932, 1, $3-46$.

28. Dorofeev, V.F.; Filatenko, A.A.; Migushova, E.F.; Udaczin, R.A.; Jakubziner, M.M. Wheat. In Flora of Cultivated Plants; Dorofeev, V.F., Korovina, O.N., Eds.; Leningrad: St. Petersburg, Russia, 1979; Volume 1, p. 346. (In Russian)

29. Tsunewaki, K. Origin and phylogenetic differentiation of common wheat revealed by comparative gene analysis. In Third International Wheat Genetics; Finlay, K.W., Shepherd, K.W., Eds.; Australian Academy of Science: Canberra, Australia, 1968; pp. 71-85.

30. Hirosawa, S.; Takumi, S.; Ishii, T.; Kawahara, T.; Nakamura, C.; Mori, N. Chloroplast and nuclear DNA variation in common wheat: Insight into the origin and evolution of common wheat. Genes Genet. Syst. 2004, 79, 271-282. [CrossRef] [PubMed]

31. Li, A.; Liu, D.; Yang, W.; Kishii, M.; Mao, L. Synthetic Hexaploid Wheat: Yesterday, Today, and Tomorrow. Engineering 2018, 4 , 552-558. [CrossRef] 
32. Liu, C.; Shi, Y.; Zhu, Y.; Chen, H.; Zhang, J.; Lin, X.; Guan, X. CpGAVAS, an integrated web server for the annotation, visualization, analysis, and GenBank submission of completely sequenced chloroplast genome sequences. BMC Genom. 2012, 13, 715. [CrossRef] [PubMed]

33. Katoh, K.; Rozewicki, J.; Yamada, K.D. MAFFT online service: Multiple sequence alignment, interactive sequence choice and visualization. Brief Bioinform. 2019, 20, 1160-1166. [CrossRef]

34. Altschul, S.F.; Gish, W.; Miller, W.; Myers, E.W.; Lipman, D.J. Basic local alignment search tool. J. Mol. Biol. 1990, 215 , 403-410. [CrossRef] 